\title{
Factors Associated with Shortening of Prehospital Delay among Patients with Acute Ischemic Stroke
}

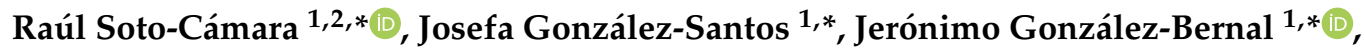 \\ Asunción Martín-Santidrian ${ }^{3}$, Esther Cubo ${ }^{3}$ and José M Trejo-Gabriel-Galán ${ }^{3}$ \\ 1 Department of Health Sciences, University of Burgos, 09001 Burgos, Spain \\ 2 Emergency Medical Service, 09200 Burgos, Spain \\ 3 Neurology Department, University Hospital of Burgos, 09006 Burgos, Spain; \\ amartins@saludcastillayleon.es (A.M.-S.); esthercubo@gmail.com (E.C.); jtrejogyg@gmail.com (J.M.T.-G.-G.) \\ * Correspondence: rscamara@ubu.es (R.S.-C.); mjgonzalez@ubu.es (J.G.S.); jejavier@ubu.es (J.G.-B.); \\ Tel.: +34-669256957 (R.S.-C.); +34-651696898 (J.G.-S.); +34-606-363553 (J.G.-B.)
}

Received: 6 October 2019; Accepted: 15 October 2019; Published: 17 October 2019

\begin{abstract}
Background: Despite recent advances in acute stroke care, only 1-8\% of patients can receive reperfusion therapies, mainly because of prehospital delay (PHD). Objective: This study aimed to identify factors associated with PHD from the onset of acute stroke symptoms until arrival at the hospital. Methods: A cross-sectional study was conducted including all patients consecutively admitted with stroke symptoms to Burgos University Hospital (Burgos, Spain). Socio-demographic, clinical, behavioral, cognitive, and contextualized characteristics were recorded, and their possible associations with PHD were studied using univariate and multivariable regression analyses. Results: The median PHD of 322 patients was $138.50 \mathrm{~min}$. The following factors decreased the PHD and time until reperfusion treatment where applicable: asking for help immediately after the onset of symptoms (OR 10.36; 95\% confidence interval (CI) 4.47-23.99), onset of stroke during the daytime (OR 7.73; 95\% CI 3.09-19.34) and the weekend (OR 2.64; 95\% CI 1.19-5.85), occurrence of stroke outside the home (OR 7.09; 95\% CI 1.97-25.55), using a prenotification system (OR 6.46; 95\% CI 1.71-8.39), patient's perception of being unable to control symptoms without assistance (OR 5.14; 95\% CI 2.60-10.16), previous knowledge of stroke as a medical emergency (OR 3.20; 95\% CI 1.38-7.40), call to emergency medical services as the first medical contact (OR 2.77; 95\% CI 1.32-5.88), speech/language difficulties experienced by the patient (OR 2.21;95\% CI 1.16-4.36), and the identification of stroke symptoms by the patient (OR 1.98; 95\% CI 1.03-3.82). Conclusions: The interval between the onset of symptoms and arrival at the hospital depends on certain contextual, cognitive, and behavioral factors, all of which should be considered when planning future public awareness campaigns.
\end{abstract}

Keywords: ischemic stroke; prehospital delay; time factors; admission delay; early arrival

\section{Introduction}

Stroke is one of the most frequent causes of mortality, dependency, and disability among adults worldwide, leading to high economic costs for the patients, their families, and health services [1-3].

Despite recent advances in acute stroke care that can improve clinical outcomes [4,5], only 1-8\% of patients can reach the hospital for reperfusion therapies [6-8], which is far from the minimum expected to decrease the effect of stroke at the population level significantly [9]. The term "time is brain" emphasizes the importance of the time in nervous tissue damage in acute stroke. The interval between the onset of symptoms and the arrival at the hospital greatly influences the treatment efficacy and the final prognosis of the patient [10]. Most of the studies on prehospital delay (PHD) have focused on the identification of the socio-demographic, clinical, and contextual characteristics of patients who 
choose not to seek immediate treatment [11-14]. However, the PHD can also be affected by other behavioral and cognitive factors and features that have hardly been studied [15].

This study aimed to identify socio-demographic, clinical, behavioral, cognitive, and contextual factors that influence the early arrival of patients with acute stroke at the hospital.

\section{Methods}

This one-year cross-sectional prospective study, part of a larger project on PHD, stroke awareness, and treatment, was conducted at the Neurological Department, Burgos University Hospital, a large-scale tertiary care center in north Spain, with a well-established intravenous thrombolysis program and stroke unit. Emergency medical service (EMS) was provided by the regional Emergency Medical Dispatch Centers, which responded to the European phone number (112) and used validated and standardized protocols for stroke screening [10]. No public awareness campaigns on stroke took place before or during the study period.

The study included patients of both sexes, aged $\geq 18$ years, who were consecutively admitted to the emergency department (ED) during the first year, within $12 \mathrm{~h}$ after the onset of acute stroke. The diagnosis of stroke was as per the definition of the World Health Organization, and cerebral infarction based on neuroimaging (computed tomography (CT) or magnetic resonance imaging) results was differentiated from intraparenchymal hemorrhage [10]. Exclusion criteria for patients included the following: in-hospital stroke, episodes in which diagnostic workup was inconclusive or showed probable causes other than stroke, time of symptom onset was unknown, inability to communicate data directly because of speech or cognitive deficits, no follow-up in the first hours of admission, and refusal to provide informed consent. In the case of recurrent strokes during the study period, only the first event was included. The data were obtained without any prespecified hypotheses, and the sample size was not previously determined.

Patients were informed of the purpose of the study and invited to participate. In case of acceptance, they were asked to sign the informed consent. Patients answered a structured questionnaire for 15-20 $\mathrm{min}$ in a face-to-face interview within $72 \mathrm{~h}$ of admission to minimize in-hospital stroke education and information loss. The medical records were reviewed to obtain complete data, confirmed by participants. The study was approved by the Institutional Review Board (IRB 1479).

The primary outcome was PHD, the time in minutes from the onset of symptoms to the arrival at the hospital. The time of stroke onset was the moment when the patient or a witness first noticed a neurological deficit. The time of arrival was the earliest time routinely documented in the electronic medical record of the ED. The PHD was divided into two subperiods: the initial part or decision delay (DD), i.e., the interval between the symptom onset and first contact to ask for help depending on the patient, and the final part or transport delay (TD), i.e., the interval from the request for assistance to arrival at the hospital.

Five domains were evaluated: socio-demographic features, clinical characteristics, behavioral response to symptoms, cognitive response to symptoms, and the context in which the stroke occurred. Stroke severity was assessed during admission using the "National Institute of Health Stroke Scale" (NIHSS) [16], representing the condition as mild to moderate $(\leq 16)$ or severe $(>16)$; if no score was documented, it was calculated retrospectively by reviewing the chart of the patient's documented neurologic examination on hospital arrival. The degree of disability was previously assessed using the "modified Rankin scale," representing the condition as independent $(\leq 2)$ and dependent $(>2)$. The COPE-28 questionnaire, a situational version, was used to determine the type of coping strategy [17]. The level of self-perceived seriousness and anxiety was assessed using a five-point Likert scale. The previous knowledge of stroke was determined by at least two signs or symptoms and two risk factors; the three possible responses, of which only one was correct, were proposed to evaluate the response to a possible case. The date of onset was categorized into working days (Monday to Friday) and weekends (Saturday, Sunday, and official holidays); the time of onset was divided into morning (06:00-14:00), afternoon (14:00-22:00), and night (22:00-06:00). The terms rural and urban were defined 
as the region outside or within the boundary of the city where the hospital was located, respectively. The mode of transport was classified as an ambulance or others.

PHD was not normally distributed; therefore, for descriptive statistics, the median values and interquartile range (IQR) were calculated. The association between PHD and possible explanatory variables was assessed using either the Mann-Whitney U-test or the Kruskal-Wallis test. A forward stepwise multivariable regression analysis and binary logistic regression analysis adjusted by sex and age were performed to identify possible predictive factors for PHD greater or lesser than 210 or $360 \mathrm{~min}$, in which those variables with a $p$-value of $<0.20$ in the univariate analysis or those considered particularly relevant in the literature were included. The cutoff of 210 and $360 \mathrm{~min}$ was selected as per the time window for intravenous thrombolytic therapy, assuming an additional hour of intra-hospital delay, which would in no case exceed $270 \mathrm{~min}$ and for mechanical thrombectomy without CT perfusion, respectively [10]. A $p$-value of $<0.05$ was considered statistically significant. The statistical analysis was performed using the SPSS statistical software package Version 24.0 (IBM SPSS Inc, Chicago, IL, USA).

\section{Results}

Of the 583 eligible patients, 261 were excluded for the following reasons: arrived $12 \mathrm{~h}$ after stroke onset $(n=136)$, the stroke onset time was unknown $(n=53)$, no ischemic stroke on final diagnosis $(n=18)$, in-hospital stroke $(n=21)$, recurrent stroke $(n=19)$, no possibility of follow-up $(n=8)$, and inability to communicate data $(n=6)$. The characteristics of this group were similar to the 322 patients included in the study with respect to age and gender.

For all patients, the median PHD was 138.50 (IQR 74-328) min. The median PHD was even shorter when the patient was transported by EMS to the hospital (median $128.00 \mathrm{~min}$; IQR 71-268 $\mathrm{min}$ ). If the patients were classified by PHD, more than three-fifths of patients $(62.42 \%)$ arrived at the hospital in the first $210 \mathrm{~min}$ after symptom onset, $15.53 \%$ within $210-360 \mathrm{~min}$, and one-fifth $(22.05 \%)$ took more than $360 \mathrm{~min}$. The median DD and TD were 60.00 (IQR 10-240) min and 56.50 (IQR 35-91) min, respectively. The median TD among the 221 patients who used the EMS was 47.00 (IQR 33-74) min, which was divided into four consecutive intervals: EMS activation delay (median 5.00 (IQR 5-28) min), EMS arrival delay (median 10.00 (IQR 7-16) min), EMS delay on scene (median 15.00 (IQR 10-23) min), and patient transport delay from the scene to hospital by EMS (median 13.00 (IQR 9-38) min) (Figure 1). Considering the maximum time limits [10], 33.23\% of patients had a DD of $<15 \mathrm{~min}, 36.64 \%$ had a TD of $<45 \mathrm{~min}$, and $62.42 \%$ had a PHD of $<210 \mathrm{~min}$.

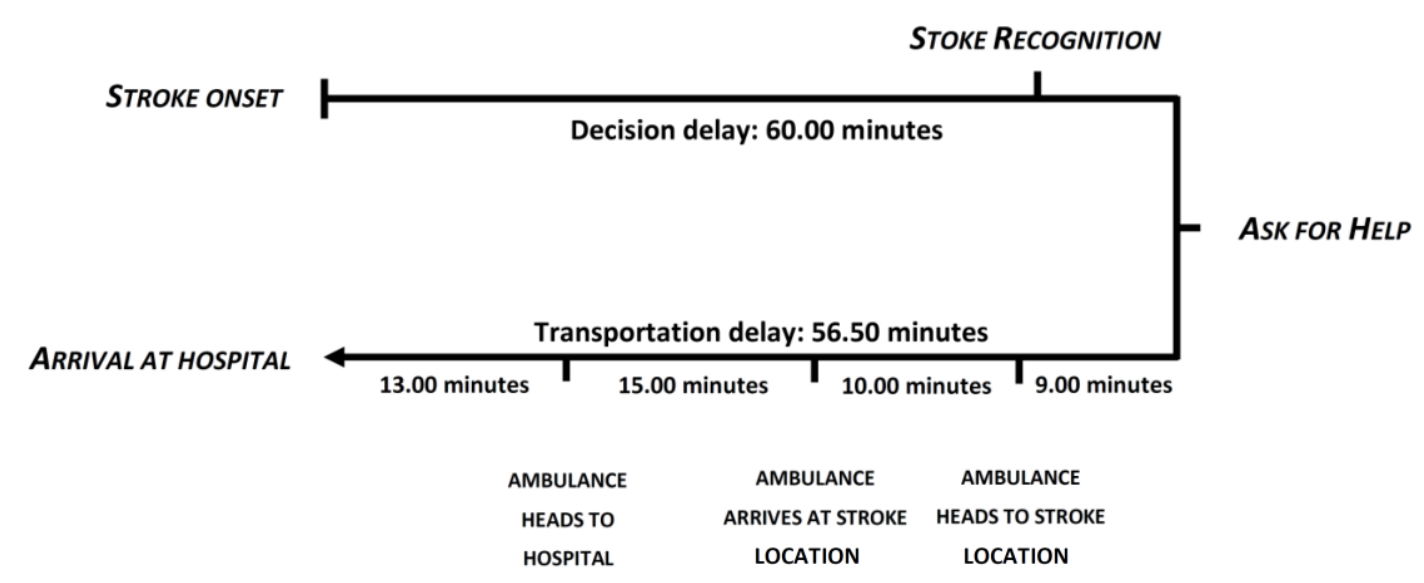

Figure 1. Time to arrival at the hospital segregated by landmarks.

Tables 1-5 show the frequencies and the univariate analysis of PHD stratified by the socio-demographic, clinical, behavioral, cognitive, and contextual characteristics of the patients. No socio-demographic or clinical factor, except speech/language alteration and headache, had a significant effect on the median time from the symptom onset to hospital admission. However, most 
of the factors in the cognitive or contextual domains were associated with significant differences in median PHD. A shorter time interval between symptom onset and arrival at the hospital was associated with the following: asking for help as the first response after the onset of symptoms, activating EMS as the first medical contact, attributing symptoms to a possible stroke, self-perceiving the situation as serious, high anxiety level, previous knowledge of stroke, knowledge of risk factors or mode of action, being accompanied, symptom onset during the daytime (06:00-22:00 h) or in an urban area, arriving at the hospital in an ambulance, or activating the prehospital stroke code. However, the longer time interval was associated with the following: thinking that the situation could be self-managed or symptoms would improve spontaneously and being alone at home.

Table 1. Time from symptom onset to hospital arrival by socio-demographic factors.

\begin{tabular}{cccc}
\hline Socio-Demographic Factors & $\boldsymbol{n}(\mathbf{\%})$ & $\begin{array}{c}\text { PHD, Minutes } \\
\text { Median (IQR) }\end{array}$ & $p$-Value \\
\hline $\begin{array}{c}\text { Age: } \\
\leq 75\end{array}$ & $118(36.65)$ & $126(73-272)$ & 0.334 \\
$>75$ & $204(63.35)$ & $148(75-356)$ & \\
\hline Sex: & $181(56.21)$ & $133(79-293)$ & 0.839 \\
Male & $141(43.79)$ & $152(65-359)$ & \\
Female & $146(45.34)$ & $132.5(84-272)$ & 0.804 \\
Marital status: & $176(54.66)$ & $150(70-344)$ & \\
Married & $211(65.53)$ & $142(75-327)$ & 0.819 \\
Not married at the moment & $111(34.47)$ & $129(72-335)$ & \\
\hline Educational level: & & & \\
No or primary study & $239(74.22)$ & $140(75-327)$ & 0.753 \\
Secondary or higher study & $83(25.78)$ & $128(70-335)$ & \\
\hline Average annual income: & & & \\
$\leq € 20.000$ & $70(21.74)$ & $190(64-401)$ & 0.511 \\
$>€ 20.000$ & $252(78.26)$ & $133(75-299)$ & \\
\hline Living arrangements: & Alone &
\end{tabular}

PHD: prehospital delay; IQR: interquartile range.

Table 2. Time from symptom onset to hospital arrival by clinical factors.

\begin{tabular}{|c|c|c|c|}
\hline Clinical Factors & n (\%) & $\begin{array}{l}\text { PHD, Minutes } \\
\text { Median (IQR) }\end{array}$ & $p$-Value \\
\hline \multicolumn{4}{|c|}{ Arterial hypertension } \\
\hline Yes & $225(69.88)$ & $139(75-332)$ & 0.754 \\
\hline No & $97(30.12)$ & $136(73-305)$ & \\
\hline \multicolumn{4}{|l|}{ Diabetes mellitus } \\
\hline Yes & $80(24.84)$ & $129.5(70-310)$ & 0.904 \\
\hline No & $242(75.16)$ & $139(74-335)$ & \\
\hline \multicolumn{4}{|l|}{ Dyslipidemia } \\
\hline Yes & $158(49.07)$ & $129(84-359)$ & 0.754 \\
\hline No & $164(50.93)$ & $151(69-299)$ & \\
\hline \multicolumn{4}{|l|}{ Overweight/obesity } \\
\hline Yes & $214(66.46)$ & $132.5(75-327)$ & 0.817 \\
\hline No & $108(33.54)$ & $168(70-333)$ & \\
\hline \multicolumn{4}{|c|}{ Cardiovascular disease } \\
\hline Yes & $159(49.38)$ & $138(75-359)$ & 0.937 \\
\hline No & $163(50.62)$ & $142(74-309)$ & \\
\hline \multicolumn{4}{|l|}{ Atrial fibrillation } \\
\hline Yes & $101(31.37)$ & $130(69-374)$ & 0.387 \\
\hline No & $221(68.63)$ & $150(80-305)$ & \\
\hline \multicolumn{4}{|l|}{ Previous stroke } \\
\hline Yes & $73(22.67)$ & $115(65-245)$ & 0.078 \\
\hline No & $249(77.33)$ & $146(79-356)$ & \\
\hline
\end{tabular}


Table 2. Cont.

\begin{tabular}{|c|c|c|c|}
\hline Clinical Factors & n (\%) & $\begin{array}{l}\text { PHD, Minutes } \\
\text { Median (IQR) }\end{array}$ & $p$-Value \\
\hline \multicolumn{4}{|l|}{ Family history of stroke } \\
\hline Yes & $114(35.40)$ & $148(85-350)$ & 0.210 \\
\hline No & $208(64.60)$ & $132.5(70-322)$ & \\
\hline \multicolumn{4}{|l|}{ Active smoker } \\
\hline Yes & $52(16.15)$ & $130.5(72-393)$ & 0.864 \\
\hline No & $270(83.85)$ & $140(75-311)$ & \\
\hline \multicolumn{4}{|l|}{ Alcohol consumption } \\
\hline Yes & 147 (45.65) & $136(80-335)$ & 0.702 \\
\hline No & $175(54.35)$ & $140(70-294)$ & \\
\hline \multicolumn{4}{|l|}{ Physical activity } \\
\hline$>3$ days per week & $148(45,96)$ & $136(78-335)$ & 0.648 \\
\hline$<3$ days per week & $174(54,04)$ & $139(71-295)$ & \\
\hline \multicolumn{4}{|l|}{ Motor symptoms } \\
\hline Yes & $215(66.77)$ & $129(67-294)$ & 0.151 \\
\hline No & 107 (33.23) & $156(95-336)$ & \\
\hline \multicolumn{4}{|l|}{ Sensitive symptoms } \\
\hline Yes & 37 (11.49) & $133(68-399)$ & 0.718 \\
\hline No & $285(88.51)$ & $139(75-314)$ & \\
\hline \multicolumn{4}{|c|}{ Speech/language disturbance } \\
\hline Yes & 207 (64.29) & $120(67-249)$ & 0.001 \\
\hline No & $115(35.71)$ & $197(92-411)$ & \\
\hline \multicolumn{4}{|c|}{ Alteration of consciousness } \\
\hline Yes & $37(11.49)$ & $167(74-342)$ & 0.533 \\
\hline No & $285(88.51)$ & $133(74-323)$ & \\
\hline \multicolumn{4}{|l|}{ Alteration of vision } \\
\hline Yes & $31(9.63)$ & $118(61-286)$ & 0.319 \\
\hline No & $291(90.37)$ & $139(75-335)$ & \\
\hline \multicolumn{4}{|l|}{ Dizziness/instability } \\
\hline Yes & $72(22.36)$ & $134.5(83-435)$ & 0.182 \\
\hline No & $250(77.64)$ & $139.5(69-281)$ & \\
\hline \multicolumn{4}{|l|}{ Headache } \\
\hline Yes & $41(12.73)$ & $170(102-486)$ & 0.035 \\
\hline No & $281(87.27)$ & $133(70-297)$ & \\
\hline \multicolumn{4}{|c|}{ Previous similar symptoms } \\
\hline Yes & $82(25,47)$ & $125.5(65-628)$ & 0.200 \\
\hline No & $240(74.53)$ & $145(78-345)$ & \\
\hline \multicolumn{4}{|c|}{ Onset mode of symptoms } \\
\hline Gradual/stepwise & $36(11.19)$ & $190.5(104-381)$ & 0.083 \\
\hline Sudden & $286(88.81)$ & $133.5(16-718)$ & \\
\hline \multicolumn{4}{|l|}{ Type of stroke } \\
\hline Ischemic & $278(86.34)$ & $135(73-328)$ & 0.513 \\
\hline Hemorrhagic & $44(13.66)$ & $158.5(84-360)$ & \\
\hline \multicolumn{4}{|c|}{ Affected cerebral hemisphere } \\
\hline Right & $121(37.58)$ & $144(71-331)$ & 0.921 \\
\hline Left & $182(56.52)$ & $133(75-333)$ & \\
\hline Bilateral & $19(5.90)$ & $184(75-286)$ & \\
\hline \multicolumn{4}{|l|}{ Stroke severity } \\
\hline NIHSS $\leq 16$ & $267(82.92)$ & $144(74-335)$ & 0.446 \\
\hline NIHSS > 16 & $55(17.08)$ & $111(75-272)$ & \\
\hline \multicolumn{4}{|c|}{ Previous level of dependence } \\
\hline$m R S>2$ & $246(76.40)$ & $141(74-328)$ & 0.826 \\
\hline$m R S \leq 2$ & $76(23.60)$ & $135.5(72-342)$ & \\
\hline
\end{tabular}

PHD: prehospital delay; IQR: interquartile range; NIHSS: National Institute of Health Stroke Scale; mRS: modified Rankin scale.

In the multivariable regression analysis, the following factors were significantly associated with a PHD of $\leq 210$ min: asking for help immediately after symptom onset by the patient (OR 10.36; 95\% confidence interval (CI) 4.47-23.99), stroke onset during the daytime (OR 7.73; 95\% CI 3.09-19.34), using a prenotification system (stroke code; OR 4.54; 95\% CI 1.77-11.64), patient's perception of controlling symptoms without any assistance (OR 4.14; 95\% CI 1.70-10.07), stroke occurrence outside 
the home (OR 3.03; 95\% CI 1.22-7.55), calling EMS as the first medical contact (OR 2.77; 95\% CI 1.32-5.88), and patient experienced speech/language difficulties (OR 2.21; 95\% CI 1.16-4.36). When the repeated analysis was performed with early arrival defined as a PHD of $\leq 360 \mathrm{~min}$, several results were consistent with those obtained for a PHD of $\leq 210 \mathrm{~min}$. The previous knowledge of stroke as a medical emergency (OR 3.20; 95\% CI 1.38-8.40), stroke onset during the weekends (OR 2.64; 95\% CI 1.59-2.85), and identification of stroke symptoms by the patients (OR 1.98; 95\% CI 1.03-3.82) were all associated with an increased likelihood of arriving at the hospital with a PHD of $\leq 360 \mathrm{~min}$ (Table 6).

Table 3. Time from symptom onset to the hospital arrival by behavioral factors.

\begin{tabular}{cccc}
\hline Behavioral Factors & $\mathbf{n ~ ( \% )}$ & $\begin{array}{c}\text { PHD, Minutes } \\
\text { Median (IQR) }\end{array}$ & $p$-Value \\
\hline $\begin{array}{c}\text { Type of coping } \\
\text { Active }\end{array}$ & $123(38.20)$ & $140(75-273)$ & 0.651 \\
Passive & $199(61.80)$ & $136(72-359)$ & \\
\hline First response after onset of symptoms: & & & \\
Asked for help & $188(58.39)$ & $91.5(56-135)$ & $<0.001$ \\
Did not ask for help & $134(41.61)$ & $289.5(198-458)$ & \\
First medical contact & $143(44.41)$ & $106(58-232)$ & $<0.001$ \\
EMS & $92(28.57)$ & $198(110-382)$ & \\
PCP & $87(27.02)$ & $150(72-397)$ & \\
Hospital & & & \\
\hline Previous use of EMS: & $186(57.76)$ & $132.5(70-335)$ & 0.714 \\
Yes & $136(42.24)$ & $141(80-307)$ & \\
No &
\end{tabular}

PHD: prehospital delay; IQR: interquartile range; EMS: emergency medical service; PCP: primary care physician.

Table 4. Time from the symptom onset to hospital arrival by cognitive factors.

\begin{tabular}{|c|c|c|c|}
\hline Cognitive Factors & $n(\%)$ & $\begin{array}{l}\text { PHD, Minutes } \\
\text { Median (IQR) }\end{array}$ & $p$-Value \\
\hline \multicolumn{4}{|l|}{ Symptoms attributed: } \\
\hline Possibly stroke & $82(25.47)$ & $95.5(55-138)$ & \multirow[t]{2}{*}{$<0.001$} \\
\hline Possibly not stroke & $240(74.53)$ & $195.5(91-389)$ & \\
\hline \multicolumn{4}{|c|}{ Self-perceived level of seriousness: } \\
\hline Not serious $(1-3)$ & $259(80.43)$ & $169(85-376)$ & \multirow[t]{2}{*}{$<0.001$} \\
\hline Serious $(4-5)$ & $63(19.57)$ & $98(53-152)$ & \\
\hline \multicolumn{4}{|l|}{ Anxiety level: } \\
\hline Low (1-3) & $216(67.07)$ & $185(83-389)$ & \multirow[t]{2}{*}{$<0.001$} \\
\hline High (4-5) & $106(32.93)$ & $108(65-193)$ & \\
\hline \multicolumn{4}{|c|}{ Thought, the situation could be self-managed: } \\
\hline Yes & $80(24.85)$ & $359(247-537)$ & \multirow{2}{*}{$<0.001$} \\
\hline No & $242(75.15)$ & $106(63-195)$ & \\
\hline \multicolumn{4}{|c|}{ Thought, symptoms would improve: } \\
\hline Yes & $95(29.50)$ & $329(193-485)$ & \multirow{2}{*}{$<0.001$} \\
\hline No & $227(70.50)$ & $106(63-199)$ & \\
\hline \multicolumn{4}{|c|}{ Previous knowledge of stroke: } \\
\hline Yes & $179(55.59)$ & $125(71-265)$ & \multirow[t]{2}{*}{0.009} \\
\hline No & $143(44.41)$ & $184(84-425)$ & \\
\hline \multicolumn{4}{|c|}{ Previous knowledge of stroke risk factors: } \\
\hline Yes & $168(52.17)$ & $125(67-266)$ & \multirow[t]{2}{*}{0.011} \\
\hline No & $154(47.83)$ & $184(86-401)$ & \\
\hline \multicolumn{4}{|c|}{ Previous knowledge of acting after a stroke: } \\
\hline Yes & $112(34.78)$ & $76(50-151)$ & \multirow[t]{2}{*}{$<0.001$} \\
\hline No & $210(65.22)$ & $196.5(106-421)$ & \\
\hline
\end{tabular}

PHD: prehospital delay; IQR: interquartile range. 
Table 5. Time from symptom onset to hospital arrival by contextual factors.

\begin{tabular}{|c|c|c|c|}
\hline Contextual Factors & n $(\%)$ & $\begin{array}{l}\text { PHD, Minutes } \\
\text { Median (IQR) }\end{array}$ & $p$-Value \\
\hline \multicolumn{4}{|c|}{ Person who recognized symptoms: } \\
\hline Patient & $204(63.35)$ & $128(71-296)$ & 0.057 \\
\hline Witness & $118(36.65)$ & $180(83-397)$ & \\
\hline \multicolumn{4}{|c|}{ Person who requested assistance: } \\
\hline Patient & $175(54.35)$ & $150(75-376)$ & 0.140 \\
\hline Witness & $147(45.65)$ & $125(71-267)$ & \\
\hline \multicolumn{4}{|l|}{ Situation in which found: } \\
\hline Alone & $88(27.33)$ & $257.5(117-446)$ & $<0.001$ \\
\hline Accompanied & $234(72.67)$ & $115(65-250)$ & \\
\hline \multicolumn{4}{|l|}{ Time of day: } \\
\hline Morning (06:00-14:00) & $152(47.20)$ & $146.5(72-335)$ & $<0.001$ \\
\hline Afternoon (14:00-22:00) & $122(37.89)$ & $110(65-210)$ & \\
\hline Night (22:00-08:00) & $48(14.91)$ & $289(112-650)$ & \\
\hline \multicolumn{4}{|l|}{ Type of day: } \\
\hline Working day & $219(68.01)$ & $142(80-390)$ & 0.093 \\
\hline Weekend & $103(31.99)$ & $132(67-251)$ & \\
\hline \multicolumn{4}{|l|}{ Onset of symptoms at: } \\
\hline Home & $244(75.76)$ & $184(91-396)$ & $<0.001$ \\
\hline Other localization & $78(24.24)$ & $92.5(55-104)$ & \\
\hline \multicolumn{4}{|l|}{ Area: } \\
\hline Urban & $191(59.32)$ & $116(56-359)$ & 0.005 \\
\hline Rural & $131(40.68)$ & $152(105-309)$ & \\
\hline \multicolumn{4}{|l|}{ Mode of arrival: } \\
\hline Ambulance & $221(68.63)$ & $128(71-268)$ & 0.046 \\
\hline Others & $101(31.37)$ & $184(86-404)$ & \\
\hline \multicolumn{4}{|c|}{ Prehospital stroke code activated } \\
\hline Yes & $84(26.09)$ & $87(58-135)$ & $<0.001$ \\
\hline No & $238(73.91)$ & $196.5(95-400)$ & \\
\hline
\end{tabular}

PHD: prehospital delay; IQR: interquartile range; EMS: emergency medical service.

Table 6. Multivariable regression analysis of independent predictors of delay $\leq 210 \mathrm{~min}$ and $\leq 360 \mathrm{~min}$ from the symptom onset to hospital arrival.

\begin{tabular}{|c|c|c|c|c|}
\hline \multirow{2}{*}{ Factors } & \multicolumn{2}{|c|}{ PHD $\leq 210 \mathrm{~min}$} & \multicolumn{2}{|c|}{$\mathrm{PHD} \leq 360 \mathrm{~min}$} \\
\hline & $\mathrm{OR}^{\mathrm{a}}(95 \% \mathrm{CI})$ & $p$-Value & OR $(95 \% \mathrm{CI})$ & $p$-Value \\
\hline Speech/language disturbance: Yes & $2.21(1.16-4.36)$ & 0.023 & - & - \\
\hline First response after onset of symptoms: Asked for help & $10.36(4.47-23.99)$ & $<0.001$ & - & - \\
\hline Symptoms attributed: Possibly stroke & - & - & $1.98(1.03-3.82)$ & 0.041 \\
\hline Thought the situation could be self-managed: No & $4.14(1.70-10.07)$ & 0.002 & $5.14(2.60-10.16)$ & $<0.001$ \\
\hline Previous knowledge of acting after a stroke: Yes & - & - & $3.20(1.38-7.40)$ & 0.007 \\
\hline Time of day: Day (08:00-22:00) & $7.73(3.09-19.34)$ & $<0.001$ & $3.79(1.71-8.39)$ & 0.001 \\
\hline Type of day: Weekend & & - & $2.64(1.19-5.85)$ & 0.017 \\
\hline Onset of symptoms at home: No & $3.03(1.22-7.55)$ & 0.017 & 7.09 (1.97-25.55) & 0.003 \\
\hline First medical contact: EMS & $2.77(1.32-5.88)$ & 0.008 & & - \\
\hline Prehospital stroke code activated: Yes & $4.54(1.77-11.64)$ & 0.002 & $6.46(1.71-24.42)$ & 0.006 \\
\hline
\end{tabular}

PHD: prehospital delay; OR: odds ratio; CI: confidence interval; EMS: emergency medical service. ${ }^{\text {a }}$ Odds ratio greater than 1 indicates a positive association with delay $\leq 210$ and $\leq 360 \mathrm{~min}$.

\section{Discussion}

The obtained median PHD after the onset of symptoms was lesser than that obtained by other studies $[12,15,18-20]$. No differences were observed between the median DD and TD. The cutoff time used in some studies for patients to reach hospital was 24 or $48 \mathrm{~h}$ or other periods [11,12,21,22]; 
however, we selected 12 has the cutoff time, as the patients are more likely to have thrombolysis or thrombectomy [23]. Therefore, the median delay data must be interpreted with caution. During the first $12 \mathrm{~h}$, three-times more stroke patients arrived at the hospital when considered up to seven days, which is 14 -fold longer interval.

Treating stroke early can reduce in-hospital delay and TD, which is not dependent on the patient, but on motivated professionals [24]. Moreover, earlier treatment can be obtained by improving the DD, the first link in the "stroke chain of survival." However, reducing DD is most difficult because patients with variable knowledge of their disease, who may suffer an unexpected stroke, can themselves reduce their ability to recognize it and request assistance [25].

Socio-demographic and clinical factors are nonmodifiable and have been previously reported to be associated with PHD, although conflicting and inconclusive results have been obtained in some studies $[15,18,20-22]$. In this study, speech/language disorder was the only factor independently associated with a PHD of $\leq 210 \mathrm{~min}$ (OR 2.21; 95\% CI 1.16-4.36). Aphasia may be one of the most alarming symptoms and, therefore, may favor an earlier request for help, resulting in a shorter delay $[13,18,26,27]$.

Behavioral and cognitive factors are associated with the patients and therefore can prolong or reduce the PHD. These factors have not been studied previously in association with stroke delay and therefore require further examination.

Three-fifths of patients asked for help on the onset of symptoms in the first hour. The time to seek medical attention represented $51.50 \%$ of the PHD, similar to other studies $[12,18]$. If the early request for help was considered (DD $<15 \mathrm{~min}$ ) [12], only one-third of patients arrived at the hospital on time for thrombolysis. The likelihood of reaching hospital with a PHD of $<210 \mathrm{~min}$ was 10-times higher in patients who asked for help (OR 10.36; 95\% CI 4.47-23.99), increasing to 17-fold if the patient did so within the first $15 \mathrm{~min}$. The three main factors influencing the decision to seek help were the following: identifying the symptoms $(p<0.001)$, maintaining a sense of normality $(p<0.001)$, and the presence and influence of another person $(p<0.001)$; these results are consistent with those of previous studies [28]. In addition, stroke symptoms affect a patient's ability to seek help; therefore, a longer delay in PHD may be noted for a considerable number of patients. Consistent with clinical practice, when the EMS was the first medical contact after symptom onset, the likelihood of arriving on time for thrombolysis was higher (OR 2.77; 95\% CI 1.32-5.88), reducing the intra-hospital time by advancing some actions. Patients who activated the EMS had more serious stroke $(p<0.001)$. Moreover, $44.41 \%$ patients called EMS as the first medical contact, which is consistent with other studies [18,22,29], with $71.33 \%$ arriving within $210 \mathrm{~min}$ and $83.92 \%$ within $360 \mathrm{~min}$. The lack of knowledge of the role of EMS in acute stroke may be a cause for its low use. Reaching the hospital by ambulance was also associated with a shorter PHD; however, its influence decreased after analyzing other factors. This difference may be because of the previous contact with EMS in two-thirds of patients transported by ambulance to the hospital. Therefore, despite using any means of transport, PHD was greatly influenced by the first medical contact, thus increasing the use of ambulance to reach the hospital.

Patients' interpretation of symptoms was also crucial: when they thought the situation could not be self-managed, the PHD decreased to $253 \mathrm{~min}$ (OR 5.14; 95\% CI 2.60-10.16). The PHD of patients with a generally proactive attitude was not shorter because they believed they could control the situation without any assistance or the symptoms would spontaneously improve $[15,20,29,30]$. It is unlikely that stroke-induced anosognosia is responsible for underestimating the disease because the right hemisphere strokes were not associated with a higher $\operatorname{PHD}(p=0.859)$. Patients who recognized initial symptoms as stroke arrived at the hospital on time for thrombectomy without advanced neuroimaging compared with those who attributed the symptoms to other pathologies (OR 1.98; 95\% CI 1.03-3.82). However, only $73.17 \%$ of patients recognized their symptoms as a stroke and went to the hospital or called the EMS. In line with several other studies, having had a stroke or similar symptoms was associated with better recognition of the acute event $[18,22]$. Internalizing how the patients perceive a stroke can improve its detection. Despite patients having knowledge of at least two symptoms or two 
risk factors in more than half of all cases, only $25.47 \%$ were able to identify the symptoms during its onset. Previous knowledge of responding after a stroke was associated with on-time arrival at the hospital for thrombectomy without advanced neuroimaging (OR 3.20; 95\% CI 1.38-7.40). When the patients having prior experience of stroke were asked about what they had done previously on the onset of symptoms, 77 patients $(78.57 \%)$ reported having gone to the hospital directly or having called the EMS $(p=0.038)[21,22,31]$. Despite having a low level of previous knowledge $(34.78 \%)$, the findings highlight the ability of patients to translate the knowledge automatically into action [32]. A history of previous strokes can improve knowledge, but not behavior, indicating the complexity of the challenge. The awareness of stroke symptoms and risk factors can decrease the PHD; however, it is not enough because its influence disappears when analyzed together with other factors. More use of existing devices that facilitate the request for assistance or novel ones that detect stroke and automatically issue an alert can reduce PHD.

Other factors influence the PHD depending on how and when the stroke occurred. In line with other studies, an association between stroke occurring outside the home and early arrival at the hospital was observed (OR 3.03; 95\% CI 1.22-7.55; OR 7.09; 95\% CI 1.95-25.55). When the stroke occurs in public places, symptom onset is more likely witnessed by family members, friends, or bystanders who often take a more active approach and request medical assistance quickly [33]. Patients having a stroke during the daytime (06:00-22:00) were admitted earlier than those having one during the nighttime (22:00-06:00) (OR 7.73; 95\% CI 3.09-19.34) because it is difficult to recognize at night at home and patients often wait to recover spontaneously $[26,27,34,35]$. Moreover, there is a possibility that patients are alone at home and unable to ask for assistance. However, some studies showed that stroke symptoms appearing either during the nighttime or daytime do not have a statistically significant association with PHD [11,15]. Stroke onset during the weekend increased the likelihood of early hospitalization in time for thrombectomy with no advanced neuroimaging (OR 2.64; 95\% CI 1.19-5.85). Moreover, the unavailability of the primary care physician on the weekend may prompt patients to go directly to the hospital ED to avoid delays [18,27]; this should be promoted. If the prehospital recognition and transfer protocol (stroke code) were activated, patients arrived at the hospital sooner (OR 6.46; 95\% CI 1.71-24.42) [18,36]. The same factor could be confusing because its activation is more frequent if the EMS is the first medical contact or if the patient arrives at the hospital on time for fibrinolysis or mechanical thrombectomy.

Public awareness campaigns on stroke have shown little success to date [37]. These campaigns must be updated and include the cognitive, contextual, and behavioral factors identified in this study, as well as the recent increase in the time window for reperfusion therapy $[5,38]$. Their main targets are not only at-risk patients, but also the general population, which can witness a stroke attack and should be aware of the risk with age.

This study had some limitations: It was performed at a third-level hospital, and additional analyses, including the indications of mechanical thrombectomy published in 2018, were not performed because the study had been completed prior to its publication. The strengths of this study were the consecutive, rather than retrospective, nature at the time of stroke and the detailed analysis of the PHD factors associated with the patients, some of which were not studied previously.

\section{Conclusions}

This study identified different contextual, cognitive, and behavioral factors that decrease the PHD and the time until reperfusion treatment. It is necessary to develop public awareness campaigns, wherein asking for help should be the first response after the onset of stroke symptoms. Telestroke and new neuroimaging techniques for reperfusion have improved the diagnosis and treatment of stroke occurring at nighttime or in rural areas. The activation of the prenotification system (stroke code) can help patients arrive at the hospital sooner; therefore, all health professionals must know when and how to use it. 
Author Contributions: Conceptualization: R.S.-C., J.G.-B., A.M.-S., and J.M.T.-G.-G.; methodology: R.S.-C., J.G.-B., and J.M.T.-G.-G.; software: R.S.-C.; validation: R.S.-C., J.G.-S., and J.G.-B.; formal analysis: R.S.-C., J.G.-S., and J.G.-B.; investigation: R.S.-C., J.G.-S., J.G.-B., J.M.T.-G.-G., and A.M.-S.; resources: R.C.-S., J.G.-S., and J.G.-B.; data curation: R.C.-S., J.G.-S., and J.G.-B.; writing, original draft preparation, R.S.-C. and J.G.-B.; writing, review and editing: R.S.C., J.G.S., J.G.B., A.M.S., E.C., and J.M.T.G.G.; visualization, R.S.-C., J.G.-S., J.G.-B., E.C., A.M.-S., and J.M.T.-G.-G.; supervision: R.S.-C. and J.G.-B.; project administration: R.S.-C. and J.G.-B.

Funding: This research received no external funding.

Conflicts of Interest: The authors declare no conflict of interest.

\section{References}

1. Thrift, A.G.; Cadilhac, D.A.; Thayabaranathan, T.; Howard, G.; Howard, V.J.; Rothwell, P.M.; Donnan, G.A. Global stroke statistics. Int. J. Stroke 2017, 12, 13-32. [CrossRef]

2. Benjamin, E.J.; Blaha, M.J.; Chiuve, S.E.; Cushman, M.; Das, S.R.; Deo, R.; De Ferranti, S.D.; Floyd, J.; Fornage, M.; Gillespie, C.; et al. Heart Disease and Stroke Statistics-2017 Update: A Report from the American Heart Association. Circulation 2017, 135, 146-603. [CrossRef]

3. Johnson, C.O. Global, regional, and national burden of stroke, 1990-2016: A systematic analysis for the Global Burden of Disease Study 2016. Lancet Neurol. 2019, 18, 439-458. [CrossRef]

4. Ahmed, N.; Wahlgren, N.; Grond, M.; Hennerici, M.; Lees, K.R.; Mikulik, R.; Parsons, M.; Roine, R.O.; Toni, D.; Ringleb, P.; et al. Implementation and outcome of thrombolysis with alteplase 3-4,5 h after an acute stroke: An updated analysis from SITS-ISTR. Lancet Neurol. 2010, 9, 866-874. [CrossRef]

5. Albers, G.W.; Marks, M.P.; Kemp, S.; Christensen, S.; Tsai, J.P.; Ortega-Gutierrez, S.; McTaggart, R.A.; Torbey, M.T.; Kim-Tenser, M.; Leslie-Mazwi, T.; et al. Thrombectomy for Stroke at 6 to 16 Hours with Selection by Perfusion Imaging. N. Engl. J. Med. 2018, 378, 708-718. [CrossRef]

6. Singer, O.C.; Hamann, G.F.; Misselwitz, B.; Steinmetz, H.; Foerch, C. Time trends in systemic thrombolysis in a large hospital-based stroke registry. Cerebrovasc. Dis. 2012, 33, 316-332. [CrossRef]

7. Asaithambi, G.; Tong, X.; George, M.G.; Tsai, A.W.; Peacock, J.M.; Luepker, R.V.; Lakshminarayan, K. Acute stroke reperfusion therapy trends in the expanded treatment window era. J. Stroke Cerebrovasc. Dis. 2014, 23, 2316-2321. [CrossRef]

8. Nasr, D.M.; Brinjikji, W.; Cloft, H.J.; Rabinstein, A.A. Utilization of intravenous thrombolysis is increasing in the United States. Int. J. Stroke 2013, 8, 681-686. [CrossRef]

9. Hoffmeister, L.; Lavados, P.M.; Mar, J.; Comas, M.; Arrospide, A.; Castells, X. Minimum intravenous thrombolysis utilization rates in acute ischemic stroke to achieve population effects on disability: A discrete-event simulation model. J. Neurol. Sci. 2016, 365, 59-64. [CrossRef]

10. Powers, W.; Rabinstein, A.; Ackerson, T.; Adevoe, O.; Bambakidis, N.; Becker, K. 2018 Guidelines for the Early Management of Patients with Acute Ischemic Stroke: A Guideline for Healthcare Professionals From the American Heart Association/American Stroke Association. J. Vasc. Surg. 2018, 67, 1934. [CrossRef]

11. Hong, E.S.; Kim, S.H.; Kim, W.Y.; Ahn, R.; Hong, J.S. Factors associated with prehospital delay in acute stroke. Emerg. Med. J. 2011, 28, 790-793. [CrossRef]

12. Faiz, K.W.; Sundseth, A.; Thommessen, B.; Rønning, O.M. Prehospital delay in acute stroke and TIA. Emerg. Med. J. 2013, 30, 669-674. [CrossRef]

13. Madsen, T.E.; Sucharew, H.; Katz, B.; Alwell, K.A.; Moomaw, C.J.; Kissela, B.M.; Flaherty, M.L.; Woo, D.; Khatri, P.; Ferioli, S.; et al. Gender and time to arrival among ischemic stroke subjects in the Greater Cincinnati/Northern Kentucky Stroke Study. J. Stroke Cerebrovasc. Dis. 2016, 25, 504-510. [CrossRef]

14. Sim, J.; Shin, C.-N.; An, K.; Todd, M. Factors Associated with the Hospital Arrival Time in Patients with Ischemic Stroke in Korea. J. Cardiovasc. Nurs. 2016, 31, 1. [CrossRef]

15. Mandelzweig, L.; Goldbourt, U.; Boyko, V.; Tanne, D. Perceptual, social, and behavioral factors associated with delays in seeking medical care in subjects with symptoms of acute stroke. Stroke 2006, 37, 1248-1253. [CrossRef]

16. Montaner, J.; Alvarez-Sabín, J. NIH stroke scale and its adaptation to Spanish. Neurología 2006, 21, 192-202.

17. Morán, C.; Landero, R.; González, M.C.T. COPE-28: Un análisis psicométrico de la versión en Español del brief COPE. Univ. Psychol. 2010, 9, 543-552. [CrossRef] 
18. Ruiz, R.G.; Fernández, J.S.; Ruiz, R.M.G.; Bermejo, M.R.; Arias, Á.A.; del Saz Saucedo, P.; Arroyo, R.H.; Manero, A.G.; Pinto, A.S.; Muñoz, S.N.; et al. Response to symptoms and prehospital delay in stroke subjects. Is it time to reconsider stroke awareness campaigns? J. Stroke Cerebrovasc. Dis. 2017, 26, 1-8. [CrossRef]

19. Geffner, D.; Soriano, C.; Pérez, T.; Vilar, C.; Rodríguez, D. Delay in seeking treatment by subjects with stroke: Who decides, where they go, and how long it takes. Clin. Neurol. Neurosurg. 2011, 114, 21-25. [CrossRef]

20. Herkes, G.; Barr, J.; McKinley, S.; O’Brien, E. Patient Recognition of and Response to Symptoms of TIA or Stroke. Neuroepidemiology 2006, 26, 168-175.

21. Kim, Y.S.; Park, S.-S.; Bae, H.-J.; Cho, A.-H.; Cho, Y.-J.; Han, M.-K.; Heo, J.H.; Kang, K.; Kim, D.-E.; Kim, H.Y.; et al. Stroke awareness decreases prehospital delay after acute ischemic stroke in korea. BMC Neurol. 2011, 11, 2. [CrossRef]

22. Zhou, Y.; Yang, T.; Gong, Y.; Li, W.; Chen, Y.; Li, J.; Wang, M.; Yin, X.; Hu, B.; Lu, Z. Pre-hospital delay after acute ischemic stroke in central urban China: Prevalence and risk factors. Mol. Neurobiol. 2017, 54, 3007-3016. [CrossRef]

23. Goyal, M.; Demchuk, A.M.; Menon, B.K.; Eesa, M.; Rempel, J.L.; Thornton, J.; Roy, D.; Jovin, T.G.; Willinsky, R.A.; Sapkota, B.L.; et al. Randomized Assessment of Rapid Endovascular Treatment of Ischemic Stroke. N. Engl. J. Med. 2015, 372, 1019-1030. [CrossRef]

24. Jansen, I.G.H.; Mulder, M.J.H.L.; Goldhoorn, R.J.B. Endovascular treatment for acute ischaemic stroke in routine clinical practice: Prospective, observational cohort study (MR CLEAN Registry). BMJ 2018, 360, k949. [CrossRef]

25. Hand, P.; Kwan, J.; Sandercock, P. A systematic review of barriers to delivery of thrombolysis for acute stroke. Age Ageing 2004, 33, 116-121.

26. Jiang, B.; Ru, X.; Sun, H.; Liu, H.; Sun, D.; Liu, Y.; Huang, J.; He, L.; Wang, W. Pre-hospital delay and its associated factors in first-ever stroke registered in communities from three cities in China. Sci. Rep. 2016, 6, 29795. [CrossRef]

27. Palomeras, E.; Fossas, P.; Quintana, M.; Monteis, R.; Sebastian, M.; Fábregas, C.; Ciurana, A.; Ribó, M.; Cano, A.; Sanz, P.; et al. Emergency perception and other variables associated with extra-hospital delay in stroke subjects in the Maresme region (Spain). Eur. J. Neurol. 2008, 15, 329-335. [CrossRef]

28. Moloczij, N.; McPherson, K.M.; Smith, J.F.; Kayes, N.M. Help-seeking at the time of stroke: Stroke survivors' perspectives on their decisions. Health Soc. Care Community 2008, 16, 501-510. [CrossRef]

29. Eissa, A.; Krass, I.; Levi, C.; Sturm, J.; Ibrahim, R.; Bajorek, B. Understanding the reasons behind the low utilisation of thrombolysis in stroke. Australas. Med. J. 2013, 6, 152-167. [CrossRef]

30. Papapanagiotou, P.; Iacovidou, N.; Spengos, K.; Xanthos, T.; Zaganas, I.; Aggelina, A.; Alegakis, A.; Vemmos, K. Temporal trends and associated factors for pre-hospital and in-hospital delays of stroke subjects over a 16-year period: The Athens study. Cerebrovasc. Dis. 2011, 31, 199-206. [CrossRef]

31. Räty, S.; Silvennoinen, K.; Tatlisumak, T. Prehospital pathways of occipital stroke subjects with mainly visual symptoms. Acta Neurol. Scand. 2018, 137, 51-58. [CrossRef]

32. Ragoschke-Schumm, A.; Walter, S.; Haass, A.; Balucani, C.; Lesmeister, M.; Nasreldein, A.; Sarlon, L.; Bachhuber, A.; Licina, T.; Grunwald, I.Q.; et al. Translation of the 'time is brain' concept into clinical practice: Focus on prehospital stroke management. Int. J. Stroke 2014, 9, 333-340. [CrossRef]

33. Hsieh, M.J.; Tang, S.C.; Chiang, W.C.; Huang, K.Y.; Chang, A.M.; Ko, P.C.I.; Tsai, L.K.; Jeng, J.S.; Ma, M.H.M. Utilization of emergency medical service increases chance of thrombolytic therapy in patients with acute ischemic stroke. J. Formos. Med. Assoc. 2014, 113, 813-819. [CrossRef]

34. Turin, T.C.; Kita, Y.; Rumana, N.; Takashima, N.; Ichikawa, M.; Sugihara, H.; Morita, Y.; Miura, K.; Okayama, A.; Nakamura, Y.; et al. The Time Interval Window between Stroke Onset and Hospitalization and Its Related Factors. Neuroepidemiology 2009, 33, 240-246. [CrossRef]

35. Korkmaz, T.; Ersoy, G.; Kutluk, K.; Erbil, B.; Karbek Akarca, F.; Sönmez, N.; Demir, Ö.F. An evaluation of pre-admission factors affecting the admission time of subjects with stroke symptoms. Turk. J. Emerg. Med. 2010, 10, 106-111.

36. Puolakka, T.; Strbian, D.; Harve, H.; Kuisma, M.; Lindsberg, P.J. Prehospital Phase of the Stroke Chain of Survival: A Prospective Observational Study. J. Am. Heart Assoc. 2016, 5, e002808. [CrossRef] 
37. Lecouturier, J.; Rodgers, H.; Murtagh, M.J.; White, M.; Ford, G.A.; Thomson, R.G. Systematic review of mass media interventions designed to improve public recognition of stroke symptoms, emergency response and early treatment. BMC Public Health 2010, 10, 784. [CrossRef]

38. Nogueira, R.G.; Jadhav, A.P.; Haussen, D.C.; Bonafé, A.; Budzik, R.F.; Bhuva, P.; Yavagal, D.R.; Ribo, M.; Cognard, C.; Hanel, R.A.; et al. Thrombectomy 6 to 24 Hours after Stroke with a Mismatch between Deficit and Infarct. N. Engl. J. Med. 2018, 378, 11-21. [CrossRef]

(C) 2019 by the authors. Licensee MDPI, Basel, Switzerland. This article is an open access article distributed under the terms and conditions of the Creative Commons Attribution (CC BY) license (http://creativecommons.org/licenses/by/4.0/). 